\title{
La salud pública en la agenda de los gobiernos municipales de seis ciudades colombianas, periodos 2008-20II y 2012-2015*
}

\section{Public Health in the Agenda of Municipal Governments of Six Colombian Cities, 2008- 20II and 2012-2015 Periods}

\section{Saúde pública na agenda dos governos municipais de seis cidades colombianas, períodos 2008-20II e 2012-2015}

Fecha de recepción: 27-05-14 Fecha de aceptación: 01-09-14 Disponible en línea: 01-07-14 doi: 10.11144/Javeriana.rgyps13-27.spag

Cómo citar este artículo:

Molina-Marín G, Álvarez-Ochoa PA, Oquendo-Lozano T. La salud pública en la agenda de los gobiernos municipales de seis ciudades colombianas, periodos 2008-2011 y 2012-2015. Rev. Gerenc. Polít. Salud. 2014; 13(27): 62-85. http://dx.doi.org/10.11144/Javeriana.rgyps13-27.spag

\author{
Gloria Molina-Marín** \\ Paola Andrea Álvarez-Ochoa*** \\ Tatiana Oquendo-Lozano****
}

\footnotetext{
Este artículo se deriva de la investigación titulada "Decisiones en la Política y la Gestión en la Salud Pública en el ámbito municipal. Un análisis en seis ciudades colombianas en el contexto del Sistema General de Seguridad Social en Salud (2012-2014)", cuyos resultados están publicados en el libro de título Tensiones en las decisiones en salud publica en el sistema de salud colombiano. El bien común en confrontación con los intereses y prácticas particulares, publicado en el 2013. Fecha de iniciación de la investigación: febrero 20 de 2012; fecha finalización de la investigación: diciembre del 2013.

** Enfermera, Ph.D. in Health Services Management, docente de la Facultad Nacional de Salud Pública de la Universidad de Antioquia. Investigadora principal. Correo electrónico: molinag@saludpublica.udea.edu.co. Dirección: Calle 62 No. 52-59, oficina 232, Medellín, Colombia.

*** Politóloga, especialista en Cooperación Internacional, contratista de la Facultad Nacional de Salud Pública de la Universidad de Antioquia. Correo electrónico: paoalvarez8a@gmail.com

***** Gerente en Sistemas de información en Salud, contratista de la Facultad Nacional de Salud Pública de la Universidad de Antioquia. Correo electrónico: lozano0211@gmail.com
} 


\section{Resumen}

Objetivo: analizar los contenidos que en materia de salud pública incluyen los planes de desarrollo, los planes territoriales de salud y los acuerdos municipales, así como la coherencia con la situación de salud de la comunidad reflejada en su perfil epidemiológico. Metodología: se revisaron y compararon los planes de desarrollo municipales, los planes territoriales de salud de los periodos 2008-2011 y 2012-2015 y los acuerdos que los concejos municipales emitieron sobre asuntos de salud pública entre el 2008 y junio del 2013, al igual que los perfiles epidemiológicos de seis ciudades colombianas. Hallazgos: los planes de desarrollo y territoriales poseen algunas líneas estratégicas que generan políticas públicas en diversas temáticas de salud a nivel territorial, pero ninguna ciudad cuenta con una política integral en salud pública. Los acuerdos municipales no recogen suficientemente las necesidades de salud. La mayoría de las políticas y programas en salud pública no tienen continuidad de un periodo de gobierno a otro, ni se llevan a cabo procesos de seguimiento y evaluación para tomar decisiones basadas en resultados. Conclusión: en ninguna de las ciudades hay una política integral de salud pública, hay múltiples políticas y programas enfocados en temas específicos, hay discontinuidad de las políticas y programas entre periodos de gobierno.

Palabras clave: política de salud; perfil de salud; planificación en salud; descentralización en salud

\section{Abstract}

Objective: Analyzing the contents included in the development plans, territorial health plans and the municipal agreements regarding public health, as well as their coherence with the health situation of the community, as reflected by their epidemiologic profile. Methodology: We reviewed and compared the municipal development plants, the territorial health plans of the 2008-2011 and 2012-2015 periods, the agreements that the municipal councils issued on public health matters between 2008 and June, 2013, as well as the epidemiologic profiles of six Colombian cities. Findings: The development and territorial plans have some strategic guidelines that generate public policies on different health topics on a territorial level, but none of the cities has an integral policy on public health. The health needs are not sufficiently covered by the municipal agreements. Most of the policies and public health programs are not developed further from a government period to the next; monitoring and assessment programs are not carried out to take decisions based on results either. Conclusion: None of the cities has an integral public health policy; there are multiple policies and programs focused on particular topics; there is no further development on policies and programs between government periods.

Keywords: health policy; health profile; health planning; health decentralization

\section{Resumo}

Objetivo: analisar os conteúdos que em matéria de saúde pública incluem os planos de desenvolvimento, os planos territoriais de saúde e os acordos municipais, assim como a coerência com a situação de saúde da comunidade reflita no seu perfil epidemiológico. Metodologia: revisaram-se e compararam os planos de desenvolvimento municipais, os planos territoriais de saúde dos períodos 2008-2011 e 2012-2015 e os acordos que os Concelhos Municipais emitiram sobre assuntos de saúde pública entre 2008 e junho de 2013, ao igual que os perfis epidemiológicos de seis cidades colombianas. Achados: os planos de desenvolvimento e territoriais possuem algumas linhas estratégicas que geram políticas públicas em diversas temáticas de saúde no nível territorial, mas nenhuma cidade tem uma política integral de saúde pública. Os acordos municipais não atendem suficientemente as necessidades de saúde. A maioria das políticas e programas em saúde pública na tem continuidade de um período de governo para o outro, nem se leva a cabo processos de seguimento e avaliação para tomar decisões baseadas em resultados. Conclusão: em nenhuma das cidades tem uma política integral de saúde pública, tem múltiplas políticas e programas focados em temas específicos, tem descontinuidade das políticas e programas entre períodos de governo.

Palavras-chave: política de saúde; perfil de saúde; planejamento em saúde; descentralização em saúde 


\section{Introducción}

Con la Ley 100 de 1993 se estableció el Sistema General de Seguridad Social en Salud (sGsss) de Colombia, el cual se fundamenta en directrices neoliberales internacionales justificadas en la búsqueda de mejorar la cobertura, el acceso, la calidad, la equidad, la eficiencia y la sostenibilidad financiera de los sistemas de salud. Esta ley estableció el aseguramiento como medio para acceder a los servicios y para ello creó las Empresas Promotoras de Salud (EPS) públicas y privadas, responsables de proveer un Plan Obligatorio de Salud (POS) a sus afiliados a cambio de una Unidad de Pago por Capitación (UPC), es decir, una suma de dinero por persona afiliada. Asimismo, cambió el subsidio de la oferta por el subsidio de la demanda; introdujo el mercado y la competencia entre las EPS y las Instituciones Prestadoras de Servicios (IPS) públicas y privadas; redujo el papel desempeñado por el Estado y amplió la participación privada. Con ello, un mayor porcentaje de la población tiene seguro en salud y hay una mayor participación privada (1), lo cual no ha significado mejor acceso efectivo a los servicios de salud, debido a las múltiples barreras administrativas, geográficas y económicas generadas y al ánimo de lucro, principalmente de la EPS privadas $(2,3)$.

La descentralización en salud es parte central del sGsss, a través de la cual se definieron las competencias y responsabilidades para los tres niveles de gobierno (nacional, departamental y municipal) en materia de salud. Con esto, el gobierno municipal, y en particular sus autoridades de salud, son responsables del desarrollo de políticas y programas de salud pública, con la participación de otros actores como las EPS, las IPS y la comunidad, entre otros (Ley 10 de 1990, Ley 100 de 1993, Ley 715 de 2001).
Durante el desarrollo del sGsss y de la descentralización ha habido un limitado desarrollo de políticas, programas y proyectos en materia de salud pública. Las autoridades de salud han desempeñado un tímido papel en este campo. A nivel local, se reconocen falencias en el direccionamiento de la salud y en la voluntad política para asumir la rectoría del Sistema para priorizar el tema en la agenda política $(4,5)$.

Esta parte de la investigación tuvo como objetivo explorar la presencia de la salud pública en la agenda política local, para lo cual se tomó como marco de análisis las competencias municipales en materia de salud, visualizadas a través de políticas y programas puestas en marcha, las líneas estratégicas de los planes de desarrollo y de los planes territoriales de salud, así como los temas de salud pública que fueron objeto de acuerdos municipales emitidos por el Concejo en las ciudades de Barraquilla, Bogotá, Bucaramanga, Leticia, Medellín y Pasto en los periodos 2008-2011 y 2012-2015. En este sentido, se analizaron estos planes y acuerdos, la continuidad de los programas, proyectos y políticas con los cambios de gobierno, y su coherencia con los perfiles epidemiológicos y la situación de salud pública de cada ciudad. Este estudio es parte de una investigación titulada Decisiones en la política y la gestión en Salud Pública. Un análisis en seis ciudades colombinas en el contexto del Sistema General de Seguridad Social en Salud, 2012-2014, cuyos principales hallazgos están publicados en el libro Tensiones en las decisiones en Salud Pública. El Bien Común en confrontación con los intereses y prácticas particulares.

Se tomó como marco de análisis algunos conceptos teóricos sobre políticas públicas que involucran categorías como los antecedentes que permitieron la construcción de las políticas (la necesidad o el diagnóstico), los actores que la impulsaron y los que tomaron 
decisiones, las estrategias con respecto a las necesidades identificadas, el seguimiento a sus resultados y la continuidad.

\section{Políticas públicas}

Las definiciones de las políticas públicas (public policies) se pueden analizar a partir de dos corrientes: la primera de ellas define a las políticas como las respuestas del Estado a problemas sociales, como parte de sus compromisos y obligaciones. Esta idea tiene entre sus defensores a Meny y a Thoenig (6), quienes definen la política pública como "un programa de acción gubernamental en un sector de la sociedad o en un espacio geográfico". Para Thomas Dye una política pública es "todo aquello que los gobiernos deciden hacer o no hacer" (7). Salazar (8) y Vargas (9) coinciden en definir "las políticas públicas como las iniciativas, decisiones y acciones del Estado frente a situaciones socialmente problemáticas, que buscan su resolución las situaciones socialmente problemáticas son aquellas que la sociedad percibe como problemas sociales relevantes a los cuales hay que definirle soluciones mediante políticas”. Por su parte, para Maggiolo y Perozo (10) "el término políticas públicas se asocia de inmediato con asuntos del gobierno y sistemas políticos o con actividades de las instituciones públicas, que van dirigidas a tener una influencia determinada sobre la vida de los ciudadanos".

La segunda corriente la defienden aquellos autores que reconocen las políticas públicas como un conjunto de interacciones y decisiones participativas que se deben concertar con la participación de los interesados. Roth (11) afirma que la construcción de políticas no es un asunto exclusivo de los hacedores de la política (policy makers), sino un asunto que incluye a la sociedad en su conjunto. Molina y Roth (12) definen las políticas públicas como "procesos de construcción colectiva de ini- ciativas, decisiones y acciones, respaldadas y legitimadas por el Estado, para dar respuesta a problemas socialmente reconocidos, en un contexto económico, político, social y cultural específico". En este mismo sentido, para Muller (13) las políticas públicas representan no solo la forma de materializar la política, sino también de concretar el debate en lo público, el reconocimiento de una sociedad y la oportunidad de articular intenciones y acciones de diferentes actores.

Bustelo (14) reconoce cinco categorías de actores involucrados en las políticas públicas: a) patrocinadores, formuladores y responsables políticos; b) directores de programas, gestores y profesionales; c) destinatarios o beneficiarios directos e indirectos; d) otros que actúan como referentes: profesionales y responsables de políticas similares, científicos sociales y expertos; e) instituciones inter y transnacionales. La presencia de actores diversos en el desarrollo de una política implica debate y confrontación —-dadas las relaciones de poder existentes entre ellos-, lo que explica el carácter complejo y turbulento que puede llegar a tener la gestión de las políticas públicas. Sin embargo, el debate permite la democratización de las decisiones, inclusión social y reconocimiento de los ciudadanos como actores políticos.

Las políticas en salud pública implican gestión, planeación y asesoría interdisciplinaria, intersectorial e interinstitucional y una fuerte participación social, en donde los escenarios de concertación y decisión son propuestos desde uno o varios actores, con la participación del Estado como ente rector y garante del derecho a la salud. Entidades internacionales en materia de salud promueven un enfoque de políticas públicas en salud denominado "salud en todas las políticas" $(15,16)$, mediante el cual se busca la inserción de asuntos sociales, económicos, políticos, culturales e institucionales clave re- 
lacionados con la salud pública, en la agenda de las principales políticas públicas, macro y microeconómicas de los Estados y de las organizaciones supranacionales.

\section{Metodología}

La metodología fue el estudio de casos (17), tomando cada ciudad como un caso, y en cada uno se revisaron los planes de desarrollo municipales y los planes territoriales de salud de los periodos 2008-2011 y 2012-2015 de las ciudades de Barranquilla, Bogotá, Bucaramanga, Leticia, Medellín y Pasto; también se revisaron los acuerdos que los Concejos municipales emitieron sobre asuntos de salud pública entre el periodo 2008 y junio de 2013, con el fin de identificar los lineamientos y acciones de salud pública propuestos en los planes y en los acuerdos, el proceso de construcción de las políticas en salud pública a nivel local, el lugar que la salud pública ocupa en la agenda municipal y la coherencia de las decisiones de las autoridades de salud con el perfil epidemiológico y las necesidades de salud en cada ciudad. Para realizar este análisis se elaboraron guías e instrumentos de recolección y revisión de información de fuente secundaria.

Las seis ciudades elegidas fueron seleccionadas por su diferencia en su nivel de desarrollo económico, social, político e institucional, asumiendo que debían darse diferencias relacionados con esto, y teniendo en cuenta los hallazgos de un estudio previo sobre los procesos de toma de decisiones en la atención en salud (2).

Se realizó una revisión y análisis de las bases de datos de estadísticas vitales de 2010, los Registros Individuales de Procedimientos en Salud (RIPS) del Ministerio de Salud del 662007 por ciudad, con los cuales se elaboró el perfil epidemiológico. También se iden- tificaron las líneas estratégicas del Plan de Desarrollo y del Plan Territorial de Salud, y el propósito de los acuerdos del Concejo relacionados con salud pública. Con la información recogida se realizó una comparación, identificando la coherencia de las líneas de acción con el perfil epidemiológico; los procesos de gestión, ejecución y seguimiento en los programas y proyectos de salud pública y la continuidad en las acciones de los planes y los acuerdos.

La información de los planes y los acuerdos se obtuvo por medio de páginas web y de las bases de datos de los acuerdos que los concejos municipales proporcionaron al proyecto. Los datos de morbilidad infantil en menores de cinco años y de la población en general se obtuvieron de las bases de datos de los RIPs del Ministerio de la Protección Social que fueron reportados por las IPS para el año 2007; la mortalidad infantil en menores de cinco años y de la población en general se obtuvo de las estadísticas vitales del Departamento Administrativo Nacional de Estadística (DANE) del año 2011; y los principales indicadores del perfil epidemiológico de documentos oficiales publicados y/o enviados al proyecto por las secretarías departamentales/distritales y municipales de las seis ciudades.

En cada ciudad se realizaron entrevistas, de las cuales se realizó un análisis cualitativo de las características y prácticas políticas locales y la influencia de estas en la construcción y definición de políticas y programas; parte de los hallazgos están publicados en el capítulo 6 del libro titulado Tensiones en las decisiones en salud pública en el sistema de salud colombiano. El bien común en confrontación con los intereses y prácticas particulares (4), por lo cual no se incluyen en este artículo. Sin embargo, dichas entrevistas aportaron al análisis de contexto sociopolítico de las políticas y programas en salud pública y 
para orientar la búsqueda y análisis de la información de los planes de desarrollo, de salud y los acuerdos municipales.

\section{Hallazgos}

\section{Perfil epidemiológico de las seis ciudades}

El perfil epidemiológico de las seis ciudades se muestra en las tablas A1-A4 (ver anexo), en los cuales se destacan como principales causas de consulta externa de los menores de cinco años las infecciones respiratorias y gastrointestinales y el monitoreo del crecimiento y el desarrollo, entre otros (tabla A1) (18). Entre las causas de mortalidad están los trastornos del crecimiento, malformaciones congénitas, trastornos del feto y del recién nacido, infecciones respiratorias agudas y problemas nutricionales (tabla A2) (19). En la población general se destacan como causas de consulta externa las enfermedades cardiovasculares y cerebrovasculares, las infecciones respiratorias y de vías urinarias, problemas lumbares, problemas gastrointestinales y dificultades durante el embarazo y el parto, entre otras (tabla A3) (18). Entre las causas de mortalidad, además de las infecciones está las enfermedades crónicas, la isquemia del corazón y tumores (tabla A4) (19).

En Leticia, además de lo común a las otras ciudades, resaltan entre las causas de mortalidad de la infancia las deficiencias nutricionales, anemias y el retardo en el crecimiento fetal; en la población general también está el VIH/sIDA y las lesiones (tabla A2). En Medellín, además de los aspectos mencionados para todas las ciudades, se presentan entre las diez primeras causas de consulta de la población general los trastornos del comportamiento (tabla A3), y entre las causas de mortalidad agresiones, homicidios y accidentes de tránsito (tabla A4).
La tabla A5 muestra algunos de los principales indicadores de salud pública, donde destaca la mayor mortalidad infantil en la ciudad de Leticia, la mayor mortalidad materna en Bogotá y Barranquilla, coberturas de vacunación superiores al $90 \%$ en todas las ciudades con los cuatro principales biológicos del Plan Ampliado de Inmunizaciones; y mayores tasas de desnutrición en Leticia (20-26).

Líneas estratégicas de los planes territoriales de salud de Barranquilla, Bucaramanga, Pasto, Bogotá, Leticia y Medellín

A continuación se describen los contenidos en salud pública de los planes de desarrollo y de los planes de salud municipales en los periodos 2008-2011 y 2012-2015 y el listado de los acuerdos municipales sobre temas de salud desde enero del 2008 hasta junio del 2013, para cada una de las ciudades, así como las principales observaciones de la comparación entre los planes y los acuerdos con el perfil epidemiológico de cada ciudad.

\section{Barranquilla: planes, políticas públicas} y acuerdos municipales en salud pública 2008-2011 y 2012-2015. El Plan Territorial de Salud (PTS) 2008-2011 de Barranquilla se enmarca en el Plan de Desarrollo del mismo periodo, el cual tiene un enfoque de derechos e inclusión social. El marco estratégico para la salud se encuentra en la política misional "Barranquilla para la gente", que incluye inversión y gestión en salud, educación y atención a la vulnerabilidad social y física. Esta política incluye los programas de: a) aseguramiento universal, b) mejor atención a población no asegurada, c) promoción social y programas especiales, d) prestación de servicios de salud con calidad, e) liderazgo, control y vigilancia del sistema de salud y f) participación, concertación y apropiación comunitaria. La tabla 1 presenta las líneas de acción del pTs y los acuerdos municipales. 
TABLA 1. LínEAS ESTRATÉgicas de LOS PLANES TERRITORIALES DE SALUd Y ACUERDOS MUNICIPALES DE LOS PERIODOS 2008-2011 Y 2012-2015, BARRANQUILLA

\begin{tabular}{|c|c|}
\hline stratégicas 2008-2011 & Líneas estratégicas 2012-2015 \\
\hline $\begin{array}{l}\text { - Cobertura universal } \\
\text { - Servicios de salud con estándares superiores } \\
\text { de calidad } \\
\text { - Estilos de vida saludables } \\
\text { En el Plan Territorial de Salud se incluyen progra- } \\
\text { mas y proyectos que responden a las líneas estra- } \\
\text { tégicas para disminuir las muertes y prevalencia } \\
\text { de enfermedades según el perfil epidemiológico } \\
\text { de la ciudad. }\end{array}$ & $\begin{array}{l}\text { - Atención integral a la primera infancia, ado- } \\
\text { - Inclusión de la población pobre y vulnerable } \\
\text { - Educación de calidad y pertinencia } \\
\text { - Formación integral con deporte y recreación } \\
\text { - Salud con oportunidad y calidad en el servicio } \\
\text { - Vivienda digna de interés social y prioritario } \\
\text { - Atención integral a la primera infancia, ado- } \\
\text { - Inclusión de la población pobre y vulnerable } \\
\text { - Educación de calidad y pertinencia } \\
\text { - Formación integral con deporte y recreación } \\
\text { - Salud con oportunidad y calidad en el servicio } \\
\text { - Vivienda digna de interés social y prioritario }\end{array}$ \\
\hline \multicolumn{2}{|l|}{ Acuerdos municipales } \\
\hline \multicolumn{2}{|c|}{$\begin{array}{l}\text { Periodo 2008-2011 } \\
\text { - } \quad 005 \text { de 2008: saneamiento básico de caños } \\
\text { - } \quad 013 \text { de 2008: atención a las víctimas del conflicto armado } \\
\text { - } \quad 022 \text { de 2008: promueve la semana del buen trato, la convivencia y la tolerancia } \\
\text { - } \quad 029 \text { de 2008: protección integral a la mujer y a los niños y niñas } \\
\text { - } \quad 017 \text { de 2010: crea un subsidio para los servicios públicos en población vulnerable } 020 \text { de 2010: } \\
\text { observatorio de seguimiento a las políticas públicas de la ciudad } \\
\text { - } \quad 004 \text { de 2011: prevención y promoción del cáncer de cuello uterino } \\
\text { - } \quad 005 \text { de 2011: política pública de atención a la población desplazada en Barranquilla implementando } \\
\text { - } \quad 007 \text { y } 008 \text { de 2011: priorización de la gestión ambiental urbana } \\
\text { Periodo 2012 a junio del } 2013 \\
\text { - } \quad 001 \text { de 2012: implementación de la Ley de Víctimas }\end{array}$} \\
\hline
\end{tabular}

Fuente: Plan de Desarrollo Municipal y Plan Territorial de Salud Barranquilla 2008-2012 y 2012-2015. Concejo Municipal de Barranquilla, Acuerdos 2008 a junio del 2013

El Plan de Desarrollo Municipal, el Plan Territorial de Salud 2008-2011 y los acuerdos municipales emitidos son coherentes entre sí y fueron el punto de partida para los planes del 2012 al 2015, dando continuidad a algunas metas y poblaciones priorizadas, como las relacionadas con los derechos de los niños y niñas, mujeres, adultos mayores y víctimas de la violencia.

El Plan Territorial de Salud 2012-2015 fue construido participativamente, mediante mesas temáticas con organizaciones sociales y la comunidad, para llegar a consensos con respecto a las necesidades en salud y a sus posibles soluciones. El PTs es parte del plan de desarrollo distrital en el eje "Barranquilla con equidad social" y en la estrategia "Barranquilla saludable", que cuenta con cinco programas de salud: a) aseguramiento en salud, b) prestación y desarrollo de servicios de salud con calidad, c) vigilancia y control de la salud pública, d) atención primaria en salud y e) promoción social. El plan de desarrollo 
y el PTS no recogen suficientemente las necesidades que plantea el perfil epidemiológico.

Bogotá: planes, políticas públicas y acuerdos 2008-2011 y 2012-2015. El Plan Distrital de Salud (PDS) 2008-2011, del marco del proyecto político "Bogotá Positiva, para vivir mejor", se enfocó en construir proyectos para la vida con equidad y dignidad, con el propósito de que el Estado garantice el goce efectivo de los derechos (GED) a los ciudadanos. La tabla 2 muestra las líneas de acción del pDs y los acuerdos municipales del Concejo en temas relacionados con la salud pública.

TABLA 2. Líneas ESTRATÉgicas de los Planes TERritoriales de SALUd Y ACUERdos MUNICIPALES DE LOS PERIODOS 2008-2011 y 2012-2015, BOGOTÁ D.C.

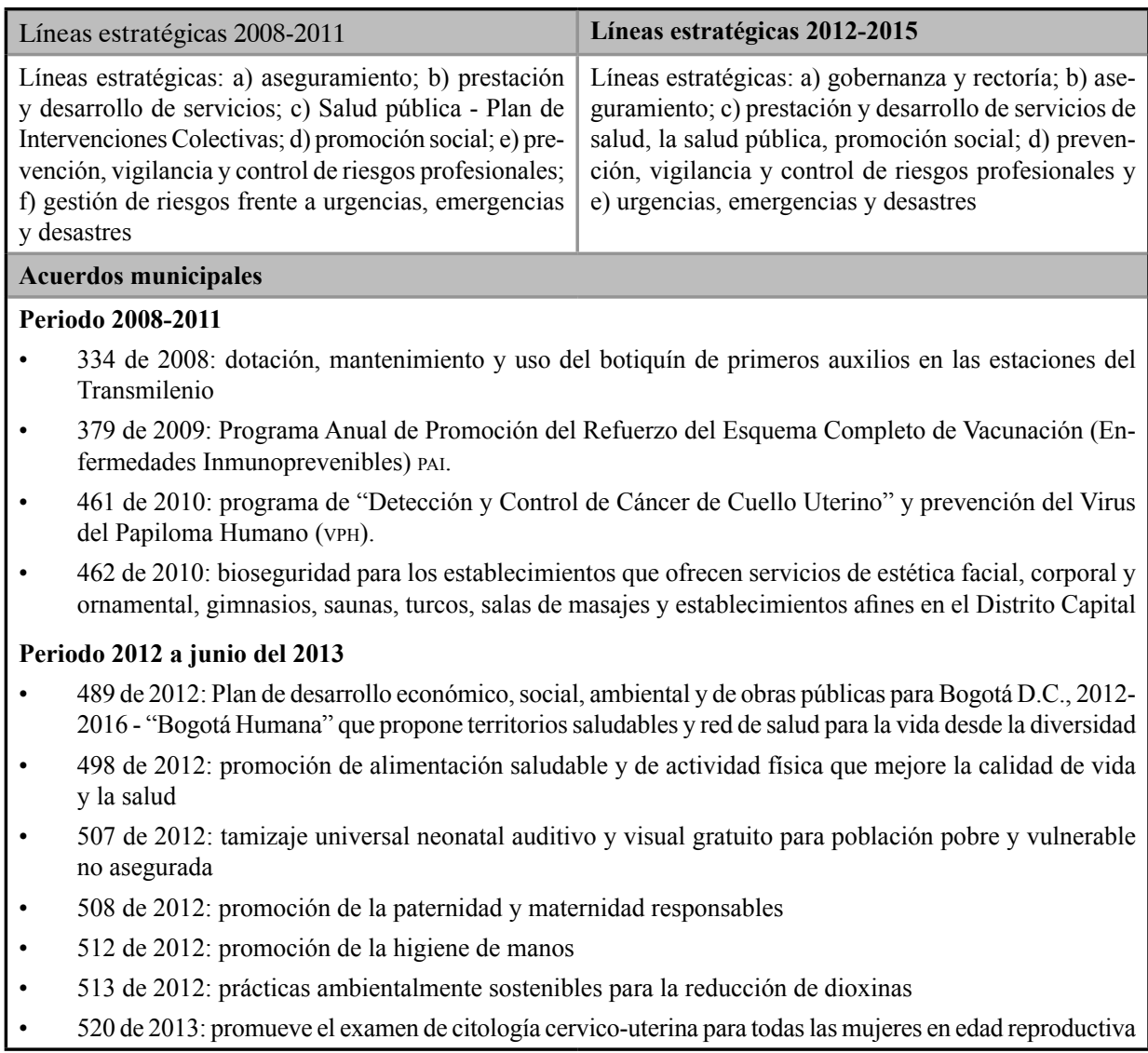

Fuente: Plan de Desarrollo Municipal y Plan Territorial de Salud Bogotá 2008-2012 y 2012-2015. Concejo Municipal de Bogotá, Acuerdos 2008 a junio del 2013

En la ciudad de Bogotá se destaca en la última década el programa Salud a su Hogar, más tarde denominado Salud a su Casa, o Salud al Territorio, fundamentados en los derechos, estructurados por ámbitos de atención (hogar, escuela, trabajo, comunidad, entre otros), desarrollados con equipos de salud interdis- ciplinarios e interinstitucionales que asumen la salud desde los determinantes sociales, las diferencias por género, ciclo vital humano, grupos poblacionales y étnicos, entre otros, bajo la estrategia de Atención Primaria en Salud. Estos programas han tenido logros importantes pero también obstáculos de tipo político, 
social y técnico, dadas las características de mercado y la segmentación de la población a través del modelo de aseguramiento del sGsss. Estas estrategias han buscado impactar el perfil epidemiológico de la población (tablas A5-A8).

\section{Bucaramanga: planes, políticas públicas y} acuerdos 2008-2011 y 2012-2015. El Plan de Desarrollo 2008-2011 tiene un enfoque económico encaminado a la productividad urbana, busca acondicionar la ciudad en función de las apuestas productivas y sus requerimientos de desarrollo social. El Plan Territorial de Salud prioriza la población discapacitada, el adulto mayor, los niños y niñas, los adolescentes, los jóvenes y la población desplazada. Adicionalmente, incluye a las mujeres, los habitantes de calle, la población carcelaria, los grupos étnicos, los loteros y chanceros como poblaciones prioritarias.

Los asuntos de salud en el plan de desarrollo están plasmados en la línea estratégica "ciudad integradora, incluyente y participativa". Esta línea a su vez incluye: 1) seguridad social en salud, la cual tiene dos estrategias: a) universalización del régimen subsidiado para población del Sisben 1 y 2, y b) implementación de subsidios parciales a población del nivel 3 del Sisben; 2) salud pública. La tabla 3 describe las líneas estratégicas del Plan Territorial de Salud 2008-2011, del Plan Operativo Anual 2012-2013 y los acuerdos.

Los programas de salud pública del período 2008-2011 estuvieron alineados con las prioridades a nivel nacional. Algunas problemáticas como la prevención de muertes por agresiones, homicidios y accidentes de tránsito, así como la prevención de enfermedades respiratorias, la diabetes mellitus y los tumores del estómago, relacionadas con malos hábitos alimenticios y estilos de vida poco saludables, no se encuentran en los programas del Plan Territorial de Salud, a pesar de que son prioridad de acuerdo con el perfil epidemiológico (tablas A9-A12).
El Plan de Desarrollo 2012-2015 tiene como enfoque generar riqueza colectiva con los principios de equidad y sostenibilidad social. Con respecto a la salud busca priorizar la población vulnerable. Dentro de los programas de salud pública se encuentran dos estrategias: a) salud para todos y todas con calidad, que incluye el fortalecimiento de la salud pública, la Atención Primaria en Salud y el control de factores de riesgo del entorno; y b) saneamiento y entorno saludable, que busca la seguridad sanitaria y ambiental, con la inspección, vigilancia y control de factores de riesgo. En general, los acuerdos del periodo $2008-2011$ y los proyectos priorizados en el PTs y en el plan de desarrollo 2008-2011 recogen algunos problemas reflejados en el perfil epidemiológico.

Para el periodo 2012-2015 no se encontraron políticas y programas enfocados a prevenir las muertes por agresiones y homicidios, ni muertes materno-infantiles, que si bien se nombran como problemas de salud en el plan de desarrollo, no se ponen en marcha estrategias concretas para su intervención.

\section{Leticia: planes, políticas públicas y acuerdos} 2008-2011 y 2012-2015. El Plan de Desarrollo "De la mano con la comunidad" tiene como enfoque el desarrollo con responsabilidad y armonía entre lo económico, lo ambiental, lo social, lo cultural y lo político, y se compone de cuatro líneas: a) niñez, infancia, adolescencia y juventud, b) Derechos Humanos, Derecho Internacional Humanitario y reducción de la pobreza, c) calidad educativa y cultura ciudadana y d) prospectiva, ciencia y tecnología.

La tabla 4 presenta las líneas estratégicas de los planes territoriales de salud del 20082011 y 2012-2015, los acuerdos municipales y algunas ordenanzas dadas por la Asamblea de Amazonas, dado que Leticia depende del departamento en asuntos de salud. 
TABLA 3. LíNEAS ESTRATÉGICAS dE LOS PLANES TERRITORIALES DE SALUd Y ACUERDOS MUNICIPALES DE LOS PERIODOS 2008-2011 y 2012-2015, BUCARAMANGA

\section{Líneas estratégicas 2008-2011}

Líneas estratégicas de salud pública: a) salud infantil, b) salud sexual y reproductiva, c) salud bucal, d) salud mental, e) enfermedades trasmisibles y zoonosis, f) nutrición y seguridad alimentaria, g) seguridad sanitaria y ambiental, h) enfermedades crónicas, i) programas para la población discapacitada, j) salud y la calidad de vida de poblaciones vulnerables, k) gestión de la salud pública, y 1) atención a la población desplazada
Bucaramanga: Plan Operativo Anual (POA) de salud 2012 y 2013

Al momento de realizar esta investigación no se contaba con el Plan Territorial de Salud (PTS) 20122015 sino con Un POA 2012-2013.

Líneas estratégicas en salud del POA son: a) aseguramiento universal, b) salud infantil, c) salud sexual y reproductiva, d) salud bucal, e) salud mental, f) enfermedades crónicas y discapacidad, g) seguridad alimentaria, h) enfermedades trasmisibles y zoonosis, i) seguridad sanitaria y ambiental, j) salud laboral, k) gestión del plan de salud pública local, l) salud y calidad de vida, promoción social y m) desarrollo sostenible. En el interior de estas se detallan acciones para dar solución a las principales causas de muerte

\section{Acuerdos municipales}

\section{Periodo 2008-2011}

- 013 de 2008: crea las brigadas de emergencia

- 027 de 2008: obliga los elementos de primeros auxilios en establecimientos de comercio

- 029 de 2008: institucionaliza el día de la prevención cáncer de mama

- 051 de 2009: crea la red de prevención de embarazos en adolescentes

- 054 de 2009: política pública de atención a las mujeres víctimas de la violencia

- 083 de 2009: crea la red de prevención de la accidentalidad vial

- $\quad 087$ de 2009: crea el comité interinstitucional consultivo para la prevención de la violencia sexual y atención a niños, niñas y adolescentes víctimas de este delito

- 088 de 2009: crea los centros de escucha y orientación para atender el consumo de sustancias psicoactivas

- 091 de 2009: promueve los derechos de la población con discapacidad auditiva

- 015 de 2010: promueve la práctica de la vasectomía y el implante subcutáneo como métodos de planificación familiar

- 029 de 2010: establece acciones para prevenir el síndrome del alcoholismo fetal

- 032 de 2010: forma el consejo municipal asesor del cáncer infantil

- 050 de 2010: crea un mecanismo de coordinación interinstitucional para la atención integral de niños, niñas y adolescentes

- 053 de 2010: política pública de discapacidad

- $\quad 011$ de 2011: política pública de atención a personas con epilepsia

- 015 de 2011: política pública de prevención del consumo de sustancias psicoactivas y otro de tipo adictivos

\section{Periodo 2012 a junio del 2013}

- 020 de 2012: política pública para el control y la prevención de la obesidad y las enfermedades crónicas no trasmisibles.

Fuente: Plan de Desarrollo municipal y Plan Territorial de Salud Bucaramanga 2008-2012 y 2012-2015. Concejo Municipal de Bucaramanga, Acuerdos 2008 a junio de 2013 
TABLA 4. LíNEAS ESTRATÉGICAS DE LOS PLANES TERRITORIALES DE SALUD Y ACUERDOS MUNICIPALES DE LOS PERIODOS 2008-2011 y 2012-2015, LETICIA

\begin{tabular}{|c|c|}
\hline Líneas estratégicas 2008-2011 & Líneas estratégicas 2012-2015 \\
\hline $\begin{array}{l}\text { Las líneas estratégicas en salud pública son: a) ni- } \\
\text { ñez, infancia, adolescencia y juventud, b) Derechos } \\
\text { Humanos, Derecho Internacional Humanitario y } \\
\text { reducción de la pobreza y c) salud y protección so- } \\
\text { cial. Dentro de estas líneas estratégicas se plantean } \\
\text { acciones para enfrentar los problemas de salud } \\
\text { pública de la ciudad presenta. }\end{array}$ & $\begin{array}{l}\text { Líneas estratégicas en salud: a) protección social, b) } \\
\text { prevención y vigilancia de gestión de riesgos profe- } \\
\text { sionales, c) emergencias y desastres, e) prestación } \\
\text { y desarrollo de servicios de salud y f) salud pública } \\
\text { y aseguramiento }\end{array}$ \\
\hline \multicolumn{2}{|l|}{ Acuerdos municipales } \\
\hline \multicolumn{2}{|l|}{ Acuerdos y ordenanzas en salud pública 2008-2011 } \\
\hline \multicolumn{2}{|c|}{$\begin{array}{l}\text { En este apartado es necesario incluir las ordenanzas del departamento del Amazonas, ya que Leticia es un } \\
\text { municipio no certificado en salud y por tanto las funciones descentralizadas las asume el departamento: }\end{array}$} \\
\hline \multicolumn{2}{|c|}{$\begin{array}{l}\text { - Acuerdo } 001 \text { de 2010: crea la estampilla para el bienestar y protección a las personas de la tercera } \\
\text { edad de los niveles } 1 \text { y } 2 \text { del Sisben o quienes según evaluación socioeconómica requieran este } \\
\text { servicio para mitigar las condiciones de pobreza extrema, vulnerabilidad, aislamiento o carencia } \\
\text { de soporte social, a través del centro de vida }\end{array}$} \\
\hline \multirow{2}{*}{\multicolumn{2}{|c|}{$\begin{array}{l}\text { Ordenanza } 010 \text { de 2011: emisión de la estampilla proseguridad alimentaria y desarrollo rural del } \\
\text { departamento por el término de cinco años, en reemplazo de la estampilla proelectrificación rural } \\
\text { de Amazonas, que se destinará a la financiación exclusiva de la seguridad alimentaria y desarrollo } \\
\text { rural de Amazonas } \\
\text { Ordenanza } 026 \text { de 2011: plan de seguridad alimentaria y nutricional del departamento de Amazonas }\end{array}$}} \\
\hline & \\
\hline \multicolumn{2}{|c|}{ Acuerdos y ordenanzas en Salud Pública de enero 2012 a junio del 2013} \\
\hline \multicolumn{2}{|c|}{$\begin{array}{l}\text { - Acuerdo } 06 \text { de 2012: incorpora recursos del presupuesto de rentas y gastos del municipio de Le- } \\
\text { ticia para la vigencia fiscal de 2012, en el marco del cual se celebró convenio administrativo con } \\
\text { la gobernación de Amazonas de concurrencia en las actividades contenidas en el desarrollo de } \\
\text { políticas y estrategias de vigilancia y gestión del conocimiento en salud pública } \\
\text { - Acuerdo } 024 \text { de 2012: fondo de solidaridad y redistribución de ingresos y asignación de subsidios } \\
\text { en los servicios de acueducto, alcantarillado y aseo en el departamento de Amazonas } \\
\text { - Acuerdo } 025 \text { de 2012: fondo de gestión de riesgos de desastres del departamento de Amazonas }\end{array}$} \\
\hline
\end{tabular}

Fuente: Plan de Desarrollo Municipal y Plan Territorial de Salud, Leticia 2008-2012 y 2012-2015. Concejo Municipal de Leticia, Acuerdos 2008 a junio del 2013

En Leticia existen graves problemas de salud pública ya controlados en casi todo el país, tales como la carencia de infraestructura sanitaria básica (acueducto, alcantarillado, manejo de basuras, etc.) que afectan negativamente la salud y la calidad de vida de los habitantes.

\section{El Plan de Desarrollo 2012-2015 tiene un} enfoque de Derechos Humanos y de género, prioriza la población infantil, los adolescentes, la familia, los grupos étnicos, la población discapacitada y las mujeres. El plan cuenta con dos proyectos estratégicos: a) el plan maestro de acueducto y b) la adquisición de predios para el proyecto de vivienda de interés social. Para mitigar los problemas de salud hay cuatro líneas estratégicas: a) fortalecimiento de la política social e integral; b) municipio con compromiso ambiental; c) municipio moderno con desarrollo urbano funcional y sostenible; y d) gerencia pública eficiente. Se han desarrollado programas y acciones en salud pública con enfoque etnocultural, en lo cual participa la población indígena, líderes indígenas, técnicos en salud y tomadores de decisiones. Sin embargo, los planes de desarrollo, los planes territoriales de salud y los acuerdos municipales solo recogen algunas necesidades y prioridades del perfil epidemiológico (tablas, A13-A16). 
La mayoría de las metas de los planes de estos periodos no cuentan con estrategias concretas para ser logradas.

\section{Medellín: planes, políticas públicas y acuer-} dos 2008-2011 y 2012-2015. La Secretaría de Salud de Medellín utilizó la metodología de marco lógico para la elaboración del Plan Territorial de Salud periodo 2008-2011, tomando como base la Resolución 425 de febrero del 2008. Para este fin, se realizaron reuniones con representantes de la comunidad, sector salud, entidades y dependencias involucradas en el tema de salud y de grupos poblacionales específicos como afrodescendientes, discapacitados, LGBTI e indígenas. Igualmente participaron, con sentido de corresponsabilidad, los actores del SGSss. La tabla 5 muestra las líneas estratégicas de los planes de territoriales de salud y los acuerdos municipales emitidos por el Concejo en asuntos de salud pública.

El propósito del PTS 2008-2011 fue mejorar las condiciones de salud de los habitantes de la ciudad y lograr el acceso real y con calidad a los servicios de salud, priorizando las poblaciones más vulnerables. Este plan se enmarcó en el Plan de Desarrollo de Medellín del mismo periodo, denominado "Medellín solidaria y competitiva", como parte de la línea 2 de "Bienestar para toda la población".

La construcción del PTs 2012-2015 fue guiada por la Secretaría de Salud de Medellín, que convocó al Consejo Municipal de Seguridad Social en Salud, a los Comités de Participación Comunitaria en Salud, a las mesas de salud, a las ligas de usuarios, a grupos poblacionales especiales (LGTBI, afrodescendientes, indígenas, discapacitados, víctimas de la violencia, adultos mayores), a organizaciones de mujeres, al sector académico, EPS, IPS, entidades gubernamentales del orden departamental y municipal y otros actores relacionados con el sector salud (Inder, secretarías de Bienestar Social, Medio Ambiente, Cultura, Tránsito, Empresas Sociales del Estado), entre otros.

Se observa que los planes como los acuerdos municipales tampoco recogen suficientemente las necesidades de salud que se identifican en el perfil epidemiológico. Sin embargo, algunos programas tuvieron continuidad en ambos periodos.

\section{Pasto: planes, políticas públicas y acuerdos} 2008-2011 y 2012-2015. El Plan de Desarrollo 2008-2011 tuvo un enfoque de desarrollo humano sostenible, fundamentado en cooperación, equidad y seguridad, con cinco ejes estratégicos: a) convivencia, justicia y seguridad; b) espacio público, ordenamiento territorial y movilidad; c) equidad y humanidad; d) ambiente, servicios públicos y gestión del riesgo; e) cultura y deporte. El eje de equidad y humanidad llamado "Pasto un espacio digno" contiene siete programas de salud pública: a) aseguramiento en salud; b) prestación de servicios en salud; c) salud pública; d) servicios sociales básicos y complementarios; e) nutrición y afecto; f) jóvenes en la jugada; y g) equidad de género y derechos humanos. Los planes territoriales de salud establecen líneas estratégicas las cuales se presentan en la tabla 6 , junto con los acuerdos municipales.

Los planes de desarrollo y de salud del periodo 2008-2012 se complementan entre sí; tienen en cuenta las directrices y prioridades nacionales en salud y el enfoque de prevención y promoción para enfrentar problemas de salud pública. El Plan de Desarrollo 20122015 se enfoca en: trasformación productiva, superación de los niveles de pobreza y vulnerabilidad y mejoramiento de los índices de seguridad; integridad social con respeto, sana convivencia y garantía de los derechos civiles, económicos, sociales, políticos y culturales. 
TABLA 5. Líneas ESTRATÉgiCAS de LOS PLANES TERRITORIALES DE SALUd Y ACUERdos MUNICIPALES DE LOS PERIODOS 2008-2011 y 2012-2015, MEDELLÍN

\begin{tabular}{|c|c|}
\hline Líne & \\
\hline & $\begin{array}{l}\text { vida, b) } \\
\text { y super- } \\
\text { i salud y } \\
\text { ral para } \\
\text { Plan de }\end{array}$ \\
\hline \multicolumn{2}{|l|}{ Acuerdos municipales } \\
\hline \multicolumn{2}{|c|}{$\begin{array}{l}\text { Periodo 2008-2011 } \\
\text { - } \quad 04 \text { de 2008: establece el Centro Integrado de Servicios Sociales para adultos y adultas mayores } \\
\text { - } \quad 039 \text { de 2008: crea la política pública ambiental de intervención integral en laderas y bordes para } \\
\text { - la sostenibilidad ambiental de Medellín } \\
\text { - } 056 \text { de 2008: crea el "Programa de recuperación nutricional en Medellín", dirigido a niños/as } \\
\text { - } \quad 059 \text { de 2008: crea las "unidades móviles de salud" } \\
\text { - } \quad 03 \text { de 2009: establece las mesas ambientales en el municipio de Medellín } \\
\text { - } \quad 057 \text { de 2009: habla sobre el programa El Barrio Oxigena la Ciudad. } \\
\text { - } \quad 062 \text { de 2009: crea la política pública para la gestión de escombros en Medellín } \\
\text { - } \quad 064 \text { de 2009: establece el programa de salud oral para el adulto mayor } \\
\text { - } \quad 065 \text { de 2009: crea el programa de salud oral para la población infantil entre cero y siete años, para } \\
\text { - } \quad 035 \text { de 2010: crea el programa Siembra un Árbol, Salvemos el Planeta } \\
075 \text { de 2010: establece la mediación escolar como una estrategia alternativa para la solución de } \\
\text { conflictos en las instituciones educativas públicas y contempla acciones para fomentar espacios } \\
\text { - } \quad 077 \text { de 2010: implementa el comparendo ambiental en Medellín } \\
\text { - } \quad 05 \text { de 2011: modifica y actualiza el Acuerdo } 64 \text { de } 2005 \text { sobre la creación de la política pública de } \\
\text { - } \quad 06 \text { de 2011: programa mínimo vital de agua potable, encauzado hacia población en situación de } \\
\text { - } \quad 058 \text { de 2011: crea la política pública de atención integral a la primera infancia "Buen Comienzo", } \\
\text { dulnerabilidad y pobreza, propone tres actividades: servicio público domiciliario de acueducto y } \\
\text { alcantarillado y mínimo vital de agua potable }\end{array}$} \\
\hline
\end{tabular}

Fuente: Plan de Desarrollo Municipal y Plan Territorial de Salud Medellín 2008-2012 y 2012-2015. Concejo 74 Municipal de Medellín, Acuerdos 2008 a junio del 2013 
TABLA 6. LÍNEAS ESTRATÉgicas DE LOS PLANES TERRITORIALES DE SALUd Y ACUERDOS MUNICIPALES DE LOS PERIODOS 2008-2011 y 2012-2015, PASTO

\begin{tabular}{|l|}
\hline Líneas estratégicas de salud pública 2008-2011 \\
\hline 1) Aseguramiento en salud, 2) prestación de \\
servicios de salud y 3) salud pública. Dentro de \\
estas líneas, los ejes programáticos del pTs son: \\
a) aseguramiento, b) prestación de servicios, c) \\
salud pública, d) promoción social, e) prevención, \\
vigilancia y control de riesgos profesionales y f) \\
emergencias y desastres \\
Tiene trece planes indicativos a) aseguramiento, b) \\
prestación de servicios, c) infancia, d) salud sexualy \\
reproductiva, e) salud oral,f) salud mental, g) salud \\
ambiental y zoonosis, h) nutrición, i) enfermedades \\
crónicas no trasmisibles, j) gestión en salud pública, \\
k) promoción social, l) prevención, vigilancia y \\
control del riesgo profesional y m) emergencias \\
y desastres.
\end{tabular}

Líneas estratégicas de salud pública 2012-2015

a) Aseguramiento, b) prestación de servicios, c) salud pública, d) promoción social, e) prevención, vigilancia y control de riesgos profesionales y f) emergencias y desastres. Debido al número de enfermedades de salud pública que aún tienen prevalencia en Pasto, las acciones dentro de la línea estratégica en salud pública tienen como objetivo mitigar la prevalencia de enfermedades previsibles

Acuerdos municipales

\section{Periodo 2008-2011}

- El 022 de 2008: incluye a Pasto en el Plan departamental para el manejo empresarial de los servicios de agua y saneamiento en el departamento de Nariño

- 010 de 2009: adopta la política pública de salud mental

- 019 de 2009: adopta el comparendo ambiental en el municipio

- 031 de 2009: vinculación del municipio de Pasto al Plan departamental para el manejo de aguas y saneamiento básico en el departamento de Nariño

- 034 de 2009: Fondo municipal de Prevención y Atención de Emergencias y Desastres

- 037 de 2009: otorga beneficios para mejorar las condiciones de vida de los adultos mayores de 62 años

- 011 de 2010: institucionaliza un programa recreativo y deportivo

- 021 de 2010: crea los centros de servicio social para la atención del adulto mayor

- 022 de 2010: disposición administrativa de inclusión laboral de personas en condición de discapacidad

- 019 de 2011: Plan Decenal Educación Ambiental un camino para construcción de ciudadanía y corresponsabilidad ambiental en el territorio 2009-2019

- 026 de 2011: adopta la política pública de adolescencia y juventud

Periodo 2012 a junio 2013

- Solo se había emitido el Acuerdo del Plan Territorial de Salud 2012-2015

Fuente: Plan de Desarrollo Municipal y Plan Territorial de Salud de Pasto 2008-2012 y 2012-2015. Concejo Municipal de Pasto, Acuerdos 2008 a junio del 2013

Las líneas estratégicas del Plan son siete: a) medio ambiente y problema ambiental; b) espacio público y problema urbano; c) cultura, comportamiento ciudadano y cambio cultural; d) productividad y competitividad urbana y rural; e) progreso social incluyente; f) convivencia, seguridad, justicia y atención a víctimas; g) institucionalidad pública.
La línea de "progreso social incluyente" tiene como objetivo mejorar la calidad y cobertura en educación, salud, equidad, vivienda, deporte, recreación y actividad física. Esta línea cuenta con tres programas relacionados con los determinantes de la salud: a) desarrollo nutricional, b) trasformando la cultura de la salud y c) aseguremos nuestra salud. 
Las líneas estratégicas de los planes intentan dar respuesta a algunos problemas relacionados con el perfil epidemiológico de la población (tablas A21-A24).

\section{Discusión}

\section{Políticas y programas en salud pública como políticas públicas}

Las políticas y programas de salud pública vinculados a los planes de desarrollo y planes territoriales de salud no siempre se conciben y desarrollan como políticas públicas, las cuales por su naturaleza deberían conllevar procesos participativos, deliberativos e incluyentes que permitan incorporar y reconocer las necesidades sociales, los intereses de la comunidad y de los diferentes actores involucrados y generar espacios de concertación y debate (13), facilitando así una discusión amplia y la toma decisiones que beneficie primordialmente al colectivo. No todos los planes analizados han sido el producto de un proceso participativo, son pocos los casos en los que los representantes de los diferentes sectores han participado activamente en el desarrollo de iniciativas de políticas y programas en salud pública; lo cual es coherente con lo que plantea Vargas (9) quien afirma que han sido insuficientes los esfuerzos para lograr la articulación, participación y movilización social en la definición de políticas públicas y programas.

Por otro lado, el diagnóstico de salud de la población es uno de los principales aspectos para elaborar los planes de desarrollo y los planes de salud de cada ciudad. En este aspecto se visualizan carencias dado que las líneas estratégicas de los planes revisados no necesariamente guardan coherencia con

76 las necesidades de la comunidad y su perfil epidemiológico.
Con respecto a los acuerdos municipales, los hallazgos sugieren que la salud pública no ha sido un asunto prioritario para los concejos municipales, lo que se evidencia en el bajo número de acuerdos emitidos sobre el tema. Asimismo, los acuerdos municipales no necesariamente se emiten como políticas públicas, y se convierten en legislaciones que no se reglamentan ni se les asignan recursos, y por ello no se implementan ni generan impacto. Adicionalmente, algunas se convierten en políticas de un gobierno de turno, que no logran surtir efecto porque son modificadas o abandonadas con facilidad por el gobierno siguiente. Dentro de la teoría acerca del ciclo de las políticas públicas, se destaca la importancia de la etapa de seguimiento y evaluación de los resultados obtenidos y el impacto de las políticas y programas $(10,27$ 29). Sin embargo, la revisión de los planes y sus estrategias en materia de salud pública sugiere que estos no han sido objeto de procesos de monitoreo ni evaluación. Cada gobierno genera cambios e introduce nuevas iniciativas sin conocer los resultados ni el impacto de los planes del gobierno anterior; en este sentido, no se logra evidenciar la relación que existe entre las acciones que se desarrollan y los cambios en la situación de salud de las comunidades. Es común ver esta práctica también en los acuerdos municipales, los cuales en su mayoría son olvidados con el cambio de mandatario local, por lo cual su implementación se queda a mitad de camino. Las políticas y programas son discontinuos, debido a los cambios periódicos de gobierno, lo que desfavorece su consolidación, resultados e impacto y además limita el posicionamiento de estas en la población y el uso eficiente de los recursos, entre otros.

\section{Falta una política integral de salud pública}

En cada una de las ciudades estudiadas existen diversas políticas y programas en salud pública sobre temas específicos como 
salud materno-infantil, vacunación, salud bucal o lactancia, entre otros, que se desarrollan según las directrices nacionales. Se evidencia la falta de una política integral en salud pública en cada ciudad que trascienda los programas puntuales de cada gobierno y que articule e involucre políticamente a los diferentes actores relacionados con la salud y sus determinantes. Las diferentes dependencias de cada gobierno desarrollan políticas y programas aislados unos de otros, donde se entremezclan las motivaciones de protagonismo, los intereses de algunos actores sobre determinados temas y las buenas intenciones de atender necesidades de las comunidades.

Los hallazgos también sugieren que la falta de políticas públicas estables en salud y la poca priorización de temas de salud pública en las agendas políticas obedecen a intereses políticos y económicos locales, regionales y/o nacionales o de partidos políticos en el poder que buscan beneficios financieros. Asimismo, en ocasiones, la toma de decisiones no formula soluciones en el orden de las necesidades sociales, sino de acuerdo a las presiones políticas de los interesados en el problema. Los hallazgos de este estudio son coherentes con los reportados en diferentes trabajos sobre la descentralización en salud y sus tensiones con el sGsss, donde se ha evidenciado la poca capacidad institucional y de gestión de las autoridades de salud municipales y del gobierno local en sus conjunto $(2,4,21,24,25,30-35)$.

\section{Conclusiones}

En cada ciudad se desarrollan líneas estratégicas de los planes, políticas y programas de salud pública en temas específicos. Sin embargo, no hay una política integral en salud pública en cada ciudad que trascienda los programas puntuales de los gobiernos de turno y que involucre y articule política y técnicamente los diferentes actores relacionados son la salud pública. Los cambios de gobierno generan incertidumbre, pérdida de continuidad y de construcción de capacidad institucional para atender las necesidades de la población y cumplir las competencias que las autoridades de salud tienen derivadas del proceso de descentralización.

Las autoridades de salud en las seis ciudades objeto de estudio han desarrollado procesos de planeación con diferentes estrategias y han formulado planes de desarrollo y planes territoriales de salud bajo diferentes enfoques; entre ellos la equidad, los derechos en salud y los determinantes sociales de la salud, tomando en cuenta las directrices nacionales y poblaciones prioritarias tales como la niñez y el adulto mayor.

En las seis ciudades, la salud pública ha estado tímidamente en la agenda del Concejo Municipal; se observa una mayor actividad de esa entidad en las ciudades de Bogotá, Medellín, Barranquilla y Pasto.

Se destaca, en todas las ciudades, la discontinuidad de los planes, programas y proyectos, dados los cambios de gobierno. Igualmente, hay carencia de monitoreo y evaluación de los procesos, resultados e impactos de los diferentes planes, políticas, programas y proyectos en salud pública que permitan retroalimentar la toma de decisiones y la generación de ideas a partir de métodos de seguimiento y evaluación.

Hay programas de salud pública que se mantienen en el orden local por directriz del gobierno central ya que hacen parte de los compromisos e indicadores nacionales. Así, las necesidades en salud pública de carácter local se invisibilizan y pierden importancia por el poco seguimiento desde el ente nacional. 
Se reconocen programas de salud pública que las ciudades formulan en los planes de desarrollo, planes territoriales o por acuerdo, que en ocasiones no llegan a ser implementados porque el presupuesto asignado es poco para su ejecución o porque se utiliza para otros programas en el trascurso de la administración.

\section{Agradecimientos}

Agradecemos a las personas que concedieron las entrevistas, participaron en los grupos focales, en los foros de discusión de los resultados preliminares y a quienes proporcionaron la información sobre los planes de desarrollo y planes territoriales de salud. Igualmente, a las entidades que cofinanciaron este estudio: Colciencias, Universidad de Antioquia (CODI sostenibilidad de grupos 2012-2013), Universidad Santo Tomas — sede Medellín-, Universidad Nacional de Colombia — sede Bogotá-y la Universidad de Illinois.

\section{Referencias bibliográficas}

1. Restrepo J, Lopera J, Rodríguez S. Integración vertical en el sistema de salud colombiano: aproximaciones empíricas y análisis de doble marginalización. Borradores del CIE. 2005; 15.

2. Molina G, Ramírez A, Muñoz I, editores. Dilemas en las decisiones en la atención en salud. Ética, derechos y deberes constitucionales frente a la rentabilidad financiera en el sistema de salud colombiano, segunda edición. Bogotá: Editorial La Carreta; 2011.

3. Echeverri O. Mercantilización de los servicios de salud para el desarrollo: el caso de Colombia. Revista Panamericana de Salud Pública. 2008; 24 (3): 210-16.

4. Molina G, Ramírez A, Ruiz A, editores. Tensiones en las decisiones en salud pública en el sistema de salud colombiano: el bien común en confrontación con los intereses y prácticas particulares. Medellín: Pulso y Letra Editores; 2013.

5. Organización Panamericana de la Salud, UsAid. Función Rectora de la Autoridad Sanitaria Nacional. Desempeño y Fortalecimiento. Edición Especial No. 17, Washington: OPS, USAID; 2007.

6. Meny Y, Thoenig J-C. Las políticas públicas. Barcelona: Ariel; 1992.
7. Dye TR. Understanding Public Policy. Nueva Jersey, Estados Unidos: Prentice Hall; 2002.

8. Salazar C. Las políticas públicas. Bogotá, Colombia: Pontificia Universidad Javeriana, Facultad de Ciencias Jurídicas; 1995.

9. Vargas A. Notas sobre el estado y las políticas públicas. Bogotá: Almudena Editores; 1999.

10. Maggiolo I, Perozo J. Políticas públicas: proceso de concertación Estado-sociedad. Revista Venezolana de Gerencia [Internet]. 2007; 12 (39): 373-392 [consultado el 10 de julio del 2013]. Disponible en: http://www.scielo.org.ve/scielo.php?script $=$ sci arttext\&pid $=$ S1315-99842007000300004\&lng $=$ es \&nrm $=$ iso ISSN $1315-9984$

11. Roth A. Políticas públicas: Formulación, implementación y evaluación. Bogotá: Ediciones Auroras; 2002.

12. Molina G, Roth A. Políticas públicas en salud. En: Molina G, Roth A. Políticas públicas en salud: aproximación a un análisis. Medellín: Universidad de Antioquia, Facultad Nacional de Salud Pública; 2008.

13. Muller P. Las políticas públicas, segunda edición. Bogotá: Universidad Externado de Colombia; 2002.

14. Bustelo Ruesta M. ¿Qué tiene de específico la metodología de evaluación? En: Bañón Martínez RI. La evaluación de la acción en políticas públicas. Madrid: Díaz de Santos; 2003. p. 13-33.

15. Howard R, Gunther S. Health in All Policies: An EU Literature Review 2006-2011 and Interview with Key Stakeholders. European Union, Equity Action [Internet] [consultado el 10 de julio del 2013]. Disponible en: http: //www.equitychannel. net/uploads/HiAP\%20\%20Final\%20Report $\% 20$ May\%202012.pdf

16. Organización Mundial de la Salud (oms). Informe sobre la salud en el mundo. 2008 [Internet] [consultado el 16 de abril del 2013]. Disponible en: http: //www.who.int/whr/2008/chapter4/es/index.html.

17. Yin R. Case Study Research. Designing and Methods, segunda edición. Londres: Sage; 1994.

18. Ministerio de la Protección Social. Registros individuales de prestación de servicios de salud, 2007.

19. Departamento Administrativo Nacional de Estadística (DANE). Defunciones por grupos de edad y sexo, según departamento, municipio de residencia y grupos de causas de defunción (lista de causas agrupadas 6/67 cie-10 de ops de 2011) [Internet] [consultado el 13 de diciembre del 2012]. Disponible en: http://www.dane.gov.co/ index.php?option $=$ com_content $\&$ view $=$ article $\&$ id =1297:defunciones-no-fetales-2011-preliminar$\&$ catid=118:estadisticas-vitales.

20. Oquendo T, Gómez LM, Molina G. Caracterización sociodemográfica y epidemiológica de: Barranquilla, Bogotá, Bucaramanga, Leticia, Medellín y Pasto. En: Molina G, Ramírez A, Ruiz A, editores. Tensiones en las decisiones en salud pública en el sistema de salud colombiano: El bien común en confrontación con los intereses y prácticas particulares. Medellín: Pulso y Letra Editores; 2014. p. 79-161.

21. Gobernación de Amazonas. Informe de gestión 2011: rendición pública de cuentas sobre 
la gestión para la garantía de los derechos de los niñ@s, adolescentes y jóvenes. 2011 [Internet] [consultado el 17 de mayo del 2014]. Disponible en: http://amazonas.gov.co/apc-aafiles/37626237653038643430623162626265/INFORME_DE_GESTION_RPC_IAJ_2011_AMAZONAS_FINAL. pdf.

22. Alcaldía de Pasto, Secretaría de Salud. Plan Territorial de Salud 2012-2015 [Internet] [consultado el 18 de mayo de 2014]. Disponible en: http://www. pasto.gov.co/phocadownload/documentos2012/ salud/plan_territorial_de_salud_2012-2015.pdf.

23. Alcaldía de Medellín, Secretaría de Bienestar Social. Diagnóstico situacional de la infancia y la adolescencia en el municipio de Medellín. 2012 [Internet] [consultado el 18 de mayo de 2014]. Disponible en: http://www.medellin.gov.co/irj/go/km/ docs/wpccontent/Sites/Subportal\%20de1\%20Ciudadano/Bienestar\%20Social/Secciones/Informes/ Documentos/2012/Diagn\%C3\%B3stico\%20de $\% 20$ infancia $\% 20 \mathrm{y} \% 20$ adolescencia $\% 20$ nuevo $\% 20$ formato.pdf.

24. Programa de Naciones Unidas para el Desarrollo y Alcaldía de Bucaramanga. Bucaramanga: estado de avance de los Objetivos de Desarrollo del Milenio. 2012 [Internet] [consultado el 20 de mayo del 2014]. Disponible en: http://www.pnud.org.co/2012/ odm2012/odm_bucaramanga.pdf.

25. Medellín Cómo Vamos. Análisis de la evolución de la calidad de vida en Medellín, 2008-2011: salud [Internet] [consultado el 20 de mayo del 2014]. Disponible en: www.medellincomovamos.org/file/2032/ download/2032.

26. Ministerio de Salud y Protección Social. Freno al embarazo adolescente, meta de MinSalud. Boletín Electrónico para los Actores del Sistema de Salud en Colombia. 2013; 20 [Internet] [consultado el 20 de mayo del 2014]. Disponible en: http://www. minsalud.gov.co/sites/rid/Lists/BibliotecaDigital/ RIDE/DE/COM/Enlace_MinSalud_20.pdf.

27. Subirats J. Análisis de políticas públicas y eficacia de la administración. Madrid: Editorial Imprenta Nacional del Boletín del Estado; 1989.
28. Vila M, Chedrese L. Los concejos barriales: propuesta para el fortalecimiento democrático. Repensando la participación política desde lo local. En: Congreso Argentino de Administración Pública. Sociedad, Gobierno y Administración; Córdoba 2003, Nov 27-29. Córdoba: Universidad de Buenos Aires, Facultad de Ciencias Económicas; 2003.

29. Howlett M, Ramesh M. Studing Public Policy. Policy Cycles and Policy Subsystems. 1995. En: Molina G. An Examination of the Process of Decentralization of the Health Sector in Colombia [Doctoral thesis]. Universty of Biermingham, England; 2003.

30. Herazo, B. Pobreza y corrupción: dos obstáculos difíciles para la promoción de la salud. En: Franco Agudelo S, editores. La salud pública hoy. Enfoques y dilemas contemporáneos en salud pública. Bogotá: Universidad Nacional de Colombia; 2005.

31. Hellman J, Kaufmann D. Las captura del Estado en las economías en transición. Revista de Finanzas y Desarrollo [Internet]; 2001. Disponible en: http:// www.imf.org/external/pubs/ft/fandd/spa/2001/09/ pdf/hellman.pdf

32. Ruiz M, Acosta N, Rodríguez L, Uribe LM, León M. Experiencia de implementación de un modelo de Atención Primaria. Revista de Salud Pública. 2011; 13 (6): 885-96 [Internet] [consultado en agosto del 2013]. Disponible en: http://www.scielo. org.co/scielo.php?script $=$ sci_arttext $\&$ pid $=$ S0124$00642011000600002 \& \operatorname{lng}=$ es\&nrm $=$ iso.

33. Molina G, Rodríguez C, Montoya N, Spurgeon P. Descentralización del sector salud en Colombia. Análisis de 91 municipios. Revista Facultad Nacional de Salud Pública. 2006; 24 (1): 48-60.

34. Molina G, Spurgeon P. La descentralización del sector salud en Colombia: una perspectiva múltiple. Rev. Gestión y Política Pública. 2007; 16 (1): 171-202.

35. Molina G. Rol de los partidos políticos en la provisión de servicios de salud, Colombia 2007-2008. Revista Facultad Nacional de Salud Pública. 2009; 27 (1): 66-75. 


\section{Anexo}

TABLA A1. Causas de consulta externa en menores de cinco años de las ciudades de Barranquilla, Bucaramanga, Bogotá, Leticia, Medellín y Pasto, 2007

\begin{tabular}{|c|c|c|c|}
\hline Barranquilla & $\%$ & Bucaramanga & $\%$ \\
\hline Control de salud de rutina del niño & 10,4 & Control de salud de rutina del niño & 19,1 \\
\hline Rinofaringitis aguda (resfriado común) & 8,5 & Rinofaringitis aguda (resfriado común) & 5,1 \\
\hline Fiebre no especificada & 5,6 & $\begin{array}{l}\text { Diarrea y gastroenteritis de presunto } \\
\text { origen infeccioso }\end{array}$ & 5,0 \\
\hline $\begin{array}{l}\text { Atención y supervisión de salud de otros } \\
\text { niños o lactantes sano }\end{array}$ & 3,5 & Fiebre no especificada & 4,2 \\
\hline Examen médico general & 3,2 & $\begin{array}{l}\text { Atención y supervisión de salud de otros } \\
\text { niños o lactantes sano }\end{array}$ & 4,0 \\
\hline $\begin{array}{l}\text { Diarrea y gastroenteritis de presunto ori- } \\
\text { gen infeccioso }\end{array}$ & 2,6 & Atención medica no especificada & 2,4 \\
\hline Persona sana que acompaña al enfermo & 2,2 & Asma no especificada & 2,1 \\
\hline $\begin{array}{l}\text { Otros síntomas y signos generales espe- } \\
\text { cificados }\end{array}$ & 1,6 & Infección viral no especificada & 1,8 \\
\hline $\begin{array}{l}\text { Infección aguda de las vías respiratorias } \\
\text { superiores, no especificada }\end{array}$ & 1,6 & Examen médico general & 1,7 \\
\hline Otras causas & 60,9 & Otras causas & 54,5 \\
\hline Bogotá D. C. & $\%$ & Leticia & $\%$ \\
\hline Control de salud de rutina del niño & 17,9 & Control de salud de rutina del niño & 14,4 \\
\hline $\begin{array}{l}\text { Atención y supervisión de salud de otros } \\
\text { niños o lactantes sanos }\end{array}$ & 8,4 & $\begin{array}{l}\text { Diarrea y gastroenteritis de presunto } \\
\text { origen infeccioso }\end{array}$ & 9,4 \\
\hline Rinofaringitis aguda (resfriado común) & 6,9 & Otros exámenes generales & 9,1 \\
\hline $\begin{array}{l}\text { Diarrea y gastroenteritis de presunto ori- } \\
\text { gen infeccioso }\end{array}$ & 4,2 & $\begin{array}{l}\text { Infección aguda de las vías respiratorias } \\
\text { superiores no especificada }\end{array}$ & 7,3 \\
\hline Bronquiolitis aguda no especificada & 2,5 & Bronquiolitis aguda no especificada & 6,7 \\
\hline Examen médico general & 2,4 & Examen médico general & 6,6 \\
\hline $\begin{array}{l}\text { Consulta para atención y supervisión de la } \\
\text { salud del niño abandonado }\end{array}$ & 2,1 & $\begin{array}{l}\text { Disminución de la agudeza visual, sin } \\
\text { especificación }\end{array}$ & 5,0 \\
\hline Caries de la dentina & 1,7 & Rinofaringitis aguda (resfriado común) & 3,5 \\
\hline Fiebre, no especificada & 1,6 & Nacido vivo único & 2,5 \\
\hline Otras causas & 52,4 & Otras causas & 35,6 \\
\hline Medellín & $\%$ & Pasto & $\%$ \\
\hline Control de salud de rutina del niño & 23,1 & Control de salud de rutina del niño & 23,9 \\
\hline $\begin{array}{l}\text { Diarrea y gastroenteritis de presunto ori- } \\
\text { gen infeccioso }\end{array}$ & 4,4 & Rinofaringitis aguda (resfriado común) & 7,6 \\
\hline Rinofaringitis aguda (resfriado común) & 4,3 & $\begin{array}{l}\text { Diarrea y gastroenteritis de presunto } \\
\text { origen infeccioso }\end{array}$ & 7,1 \\
\hline Examen médico general & 2,6 & Neumonía no especificada & 6,3 \\
\hline
\end{tabular}




\begin{tabular}{|l|c|l|c|}
\hline Asma no especificada & 1,9 & $\begin{array}{l}\text { Otras deformidades congénitas de la } \\
\text { cadera }\end{array}$ & 4,7 \\
\hline $\begin{array}{l}\text { Atención y supervisión de salud de otros } \\
\text { niños o lactantes sano }\end{array}$ & 1,8 & Examen odontológico & 2,1 \\
\hline Fiebre no especificada & 1,7 & $\begin{array}{l}\text { Infección de vías urinarias en sitio no } \\
\text { especificado }\end{array}$ & 1,7 \\
\hline Infección viral no especificada & 1,5 & $\begin{array}{l}\text { Parasitosis intestinal sin otra especifi- } \\
\text { cación }\end{array}$ & 1,6 \\
\hline Otros recién nacidos pretérmino & 1,5 & $\begin{array}{l}\text { Infección intestinal viral sin otra espe- } \\
\text { cificación }\end{array}$ & 1,5 \\
\hline Otras causas & 57,2 & Otras causas & 43,6 \\
\hline
\end{tabular}

Fuente: Ministerio de la Protección Social, 2007

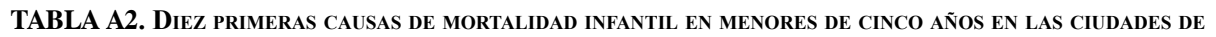
Barranquilla, Bucaramanga, Bogotá D.C., Leticia, Medellín y Pasto, 2011

\begin{tabular}{|c|c|c|c|}
\hline Causa & $\%$ & Causa & $\%$ \\
\hline \multicolumn{2}{|l|}{ Barranquilla } & \multicolumn{2}{|l|}{ Bucaramanga } \\
\hline $\begin{array}{l}\text { Malformaciones congénitas, deformida- } \\
\text { des y anomalías cromosómicas }\end{array}$ & 26,9 & $\begin{array}{l}\text { Malformaciones congénitas, deformidades } \\
\text { y anomalías cromosómicas }\end{array}$ & 42,0 \\
\hline $\begin{array}{l}\text { Trastornos respiratorios específicos del } \\
\text { periodo perinatal }\end{array}$ & 25,4 & $\begin{array}{l}\text { Otras afecciones originadas en periodo } \\
\text { perinatal }\end{array}$ & 11,6 \\
\hline Sepsis bacteriana del recién nacido & 10,7 & $\begin{array}{l}\text { Trastornos respiratorios específicos del } \\
\text { periodo perinatal }\end{array}$ & 10,1 \\
\hline $\begin{array}{l}\text { Otras afecciones originadas en periodo } \\
\text { perinatal }\end{array}$ & 8,3 & Infecciones respiratorias agudas & 5,8 \\
\hline Infecciones respiratorias agudas & 4,7 & $\begin{array}{l}\text { Feto y recién nacido afectados por com- } \\
\text { plicaciones obstétricas y traumas en el } \\
\text { nacimiento }\end{array}$ & 4,3 \\
\hline $\begin{array}{l}\text { Deficiencias nutricionales y anemias } \\
\text { nutricionales }\end{array}$ & 3,0 & Otros accidentes, inclusive secuelas & 2,9 \\
\hline $\begin{array}{l}\text { Retardo crecimiento fetal, desnutrición } \\
\text { fetal, bajo peso al nacer, gestación corta }\end{array}$ & 2,4 & Agresiones (homicidios), inclusive secuelas & 2,9 \\
\hline $\begin{array}{l}\text { Feto y recién nacido afectados por com- } \\
\text { plicaciones obstétricas y traumas en el } \\
\text { nacimiento }\end{array}$ & 1,8 & $\begin{array}{l}\text { Deficiencias nutricionales y anemias nu- } \\
\text { tricionales }\end{array}$ & 2,9 \\
\hline $\begin{array}{l}\text { Enfermedades del sistema nervioso, ex- } \\
\text { cepto meningitis }\end{array}$ & 1,8 & $\begin{array}{l}\text { Enfermedades del sistema nervioso, ex- } \\
\text { cepto meningitis }\end{array}$ & 2,9 \\
\hline Otras enfermedades del sistema digestivo & 1,8 & Síntomas, signos y afecciones mal definidas & 2,9 \\
\hline Otra & 13,3 & Otra & 11,6 \\
\hline \multicolumn{2}{|l|}{ Bogotá D. C. } & \multicolumn{2}{|l|}{ Leticia } \\
\hline $\begin{array}{l}\text { Malformaciones congénitas, deformida- } \\
\text { des y anomalías cromosómicas }\end{array}$ & 25,5 & Infecciones respiratorias agudas & 18,8 \\
\hline $\begin{array}{l}\text { Trastornos respiratorios específicos del } \\
\text { periodo perinatal }\end{array}$ & 17,6 & $\begin{array}{l}\text { Otras afecciones originadas en el periodo } \\
\text { perinatal }\end{array}$ & 18,8 \\
\hline $\begin{array}{l}\text { Otras afecciones originadas en el periodo } \\
\text { perinatal }\end{array}$ & 11,9 & $\begin{array}{l}\text { Malformaciones congénitas, deformidades } \\
\text { y anomalías cromosómicas }\end{array}$ & 18,8 \\
\hline
\end{tabular}




\begin{tabular}{|c|c|c|c|}
\hline Causa & $\%$ & Causa & $\%$ \\
\hline $\begin{array}{l}\text { Síntomas, signos y afecciones mal defi- } \\
\text { nidas }\end{array}$ & 8,2 & $\begin{array}{l}\text { Deficiencias nutricionales y anemias nu- } \\
\text { tricionales }\end{array}$ & 12,5 \\
\hline Infecciones respiratorias agudas & 7,5 & Tuberculosis, inclusive secuelas & 6,3 \\
\hline Sepsis bacteriana del recién nacido & 7,1 & $\begin{array}{l}\text { Feto y recién nacido afectados por com- } \\
\text { plicaciones obstétricas y traumas en el } \\
\text { nacimiento }\end{array}$ & 6,3 \\
\hline $\begin{array}{l}\text { Feto y recién nacido afectados por com- } \\
\text { plicaciones obstétricas y traumas en el } \\
\text { nacimiento }\end{array}$ & 4,1 & $\begin{array}{l}\text { Retardo, crecimiento fetal, desnutrición } \\
\text { fetal, bajo peso al nacer, gestación corta }\end{array}$ & 6,3 \\
\hline $\begin{array}{l}\text { Feto y recién nacido afectados por ciertas } \\
\text { afecciones maternas }\end{array}$ & 1,8 & $\begin{array}{l}\text { Enfermedad hemolítica del feto y del } \\
\text { recién nacido y Kernicterus }\end{array}$ & 6,3 \\
\hline $\begin{array}{l}\text { Retardo en el crecimiento fetal, desnutri- } \\
\text { ción fetal, bajo peso al nacer, gestación } \\
\text { corta }\end{array}$ & 1,7 & Otros accidentes, inclusive secuelas & 6,3 \\
\hline $\begin{array}{l}\text { Enfermedades del sistema nervioso, ex- } \\
\text { cepto meningitis }\end{array}$ & 1,6 & & \\
\hline Otra & 13,0 & & \\
\hline \multicolumn{2}{|l|}{ Medellín } & \multicolumn{2}{|l|}{ Pasto } \\
\hline $\begin{array}{l}\text { Malformaciones congénitas, deformida- } \\
\text { des y anomalías cromosómicas }\end{array}$ & 25,8 & $\begin{array}{l}\text { Malformaciones congénitas, deformidades } \\
\text { y anomalías cromosómicas }\end{array}$ & 27,0 \\
\hline $\begin{array}{l}\text { Trastornos respiratorios específicos del } \\
\text { periodo perinatal }\end{array}$ & 14,5 & $\begin{array}{l}\text { Trastornos respiratorios específicos del } \\
\text { periodo perinatal }\end{array}$ & 15,7 \\
\hline $\begin{array}{l}\text { Otras afecciones originadas en el periodo } \\
\text { perinatal }\end{array}$ & 13,2 & $\begin{array}{l}\text { Otras afecciones originadas en el periodo } \\
\text { perinatal }\end{array}$ & 10,1 \\
\hline Sepsis bacteriana del recién nacido & 9,4 & Otros accidentes, inclusive secuelas & 6,7 \\
\hline Infecciones respiratorias agudas & 5,5 & Síntomas, signos y afecciones mal definidas & 4,5 \\
\hline $\begin{array}{l}\text { Retardo en el crecimiento fetal, desnutri- } \\
\text { ción fetal, bajo peso al nacer, gestación } \\
\text { corta }\end{array}$ & 3,5 & $\begin{array}{l}\text { Feto y recién nacido afectados por com- } \\
\text { plicaciones obstétricas y traumas en el } \\
\text { nacimiento }\end{array}$ & 3,4 \\
\hline $\begin{array}{l}\text { Feto y recién nacido afectados por com- } \\
\text { plicaciones obstétricas y traumas en el } \\
\text { nacimiento }\end{array}$ & 3,2 & Sepsis bacteriana del recién nacido & 3,4 \\
\hline Otros accidentes, inclusive secuelas & 3,2 & Ahogamiento y sumersión accidentales & 3,4 \\
\hline $\begin{array}{l}\text { Enfermedades del sistema nervioso, ex- } \\
\text { cepto meningitis }\end{array}$ & 2,9 & Otras enfermedades respiratorias & 3,4 \\
\hline $\begin{array}{l}\text { Síntomas, signos y afecciones mal defi- } \\
\text { nidas }\end{array}$ & 1,9 & $\begin{array}{l}\text { Feto y recién nacido afectados por ciertas } \\
\text { afecciones maternas }\end{array}$ & 2,2 \\
\hline Otras & 16,8 & Otra & 20,2 \\
\hline
\end{tabular}

Fuente: DANE, 2011

TABLA A3. Causas de Consulta externa en población general mayor de Cinco años de las CiUdades de Barranquilla, Bucaramanga, Bogotá, Leticia, Medellín y Pasto, 2007

\begin{tabular}{|l|c|l|c|}
\hline Barranquilla & $\%$ & Bucaramanga & $\%$ \\
\hline Examen médico general & 2,0 & Caries de la dentina & 2,3 \\
\hline Lumbago no especificado & 2,0 & Lumbago no especificado & 1,6 \\
\hline
\end{tabular}




\begin{tabular}{|c|c|c|c|}
\hline $\begin{array}{l}\text { Vaginitis, vulvitis y vulvovaginitis en enfer- } \\
\text { medades infecciosas y parasitosis }\end{array}$ & 1,9 & $\begin{array}{l}\text { Infección de vías urinarias en sitio no } \\
\text { especificado }\end{array}$ & 1,3 \\
\hline $\begin{array}{l}\text { Infección de vías urinarias en sitio no } \\
\text { especificado }\end{array}$ & 1,7 & Examen médico general & 1,1 \\
\hline Rinofaringitis aguda (resfriado común) & 1,4 & $\begin{array}{l}\text { Diarrea y gastroenteritis de presunto ori- } \\
\text { gen infeccioso }\end{array}$ & 1,1 \\
\hline $\begin{array}{l}\text { Supervisión de embarazo de alto riesgo, } \\
\text { sin otra especificación }\end{array}$ & 1,4 & Parasitosis intestinal sin otra especificación & 1,0 \\
\hline Otros exámenes generales & 1,2 & $\begin{array}{l}\text { Persona que teme estar enferma, a quien } \\
\text { no se hace diagnóstico }\end{array}$ & 1,0 \\
\hline Síndrome del colon irritable sin diarrea & 1,1 & $\begin{array}{l}\text { Procedimiento no realizado por decisión } \\
\text { del paciente o por otras razones SAI }\end{array}$ & 0,9 \\
\hline Cefalea & 1,1 & $\begin{array}{l}\text { Consejo y asesoramiento general sobre la } \\
\text { anticoncepción }\end{array}$ & 0,9 \\
\hline Dispepsia & 0,9 & $\begin{array}{l}\text { Diabetes mellitus no insulinodependiente } \\
\text { sin mención de complicación }\end{array}$ & 0,9 \\
\hline Otras causas & 85,2 & Otras causas & 87,9 \\
\hline Bogotá D. C. & $\%$ & Leticia & $\%$ \\
\hline Hipertensión esencial (primaria) & 6,3 & $\begin{array}{l}\text { Supervisión del uso de drogas anticon- } \\
\text { ceptivas }\end{array}$ & 9,8 \\
\hline Examen médico general & 2,6 & Embarazo confirmado & 8,7 \\
\hline Caries de la dentina & 2,4 & Examen médico general & 7,5 \\
\hline Lumbago no especificado & 1,8 & Otros exámenes generales & 6,3 \\
\hline Rinofaringitis aguda (resfriado común) & 1,4 & Control de salud de rutina del niño & 4,9 \\
\hline $\begin{array}{l}\text { Infección de vías urinarias en sitio no } \\
\text { especificado }\end{array}$ & 1,3 & Parasitosis intestinal, sin otra especificación & 4,3 \\
\hline $\begin{array}{l}\text { Otros síntomas y signos generales espe- } \\
\text { cificados }\end{array}$ & 1,3 & $\begin{array}{l}\text { Disminución de la agudeza visual, sin } \\
\text { especificación }\end{array}$ & 3,3 \\
\hline Hipotiroidismo no especificado & 1,3 & $\begin{array}{l}\text { Diarrea y gastroenteritis de presunto ori- } \\
\text { gen infeccioso }\end{array}$ & 3,0 \\
\hline $\begin{array}{l}\text { Supervisión de embarazo de alto riesgo } \\
\text { sin otra especificación }\end{array}$ & 1,3 & $\begin{array}{l}\text { Consejo y asesoramiento general sobre la } \\
\text { anticoncepción }\end{array}$ & 2,4 \\
\hline $\begin{array}{l}\text { Otros dolores abdominales y los no es- } \\
\text { pecificados }\end{array}$ & 1,2 & Caries dental no especificada & 2,0 \\
\hline Otras causas & 79,0 & Otras causas & 47,7 \\
\hline Medellín & $\%$ & Pasto & $\%$ \\
\hline Hipertensión esencial (primaria) & 8,2 & Hipertensión esencial (primaria) & 4,8 \\
\hline Lumbago no especificado & 1,6 & Caries de la dentina & 4,7 \\
\hline $\begin{array}{l}\text { Supervisión de embarazo normal no } \\
\text { especificado }\end{array}$ & 1,5 & $\begin{array}{l}\text { Examen durante el periodo de crecimiento } \\
\text { rápido en la infancia }\end{array}$ & 3,4 \\
\hline Caries de la dentina & 1,4 & $\begin{array}{l}\text { Examen del estado de desarrollo del } \\
\text { adolescente }\end{array}$ & 3,2 \\
\hline $\begin{array}{l}\text { Examen del estado de desarrollo del } \\
\text { adolescente }\end{array}$ & 1,4 & $\begin{array}{l}\text { Supervisión de otros embarazos de alto } \\
\text { riesgo }\end{array}$ & 3,1 \\
\hline
\end{tabular}




\begin{tabular}{|l|c|l|c|}
\hline $\begin{array}{l}\text { Supervisión de embarazo de alto riesgo, } \\
\text { sin otra especificación }\end{array}$ & 1,3 & $\begin{array}{l}\text { Infección de vías urinarias en sitio no } \\
\text { especificado }\end{array}$ & 2,9 \\
\hline $\begin{array}{l}\text { Infección de vías urinarias en sitio no } \\
\text { especificado }\end{array}$ & 1,1 & Examen médico general & 2,3 \\
\hline Examen médico general & 1,0 & Parasitosis intestinal sin otra especificación & 2,1 \\
\hline Hipotiroidismo no especificado & 0,9 & Lumbago no especificado & 1,6 \\
\hline Gastritis no especificada & 0,9 & $\begin{array}{l}\text { Diarrea y gastroenteritis de presunto ori- } \\
\text { gen infeccioso }\end{array}$ & 1,5 \\
\hline Otras causas & 80,7 & Otras causas & 70,4 \\
\hline
\end{tabular}

Fuente: Ministerio de la Protección Social, 2007

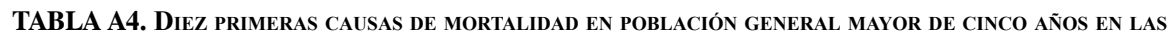
ciudades de Barranquilla, Bucaramanga, Bogotá D.C., Leticia, Medellín y Pasto, 2011

\begin{tabular}{|c|c|c|c|}
\hline Causa & $\%$ & Causa & $\%$ \\
\hline \multicolumn{2}{|l|}{ Barranquilla } & \multicolumn{2}{|l|}{ Bucaramanga } \\
\hline Enfermedades isquémicas del corazón & 15,0 & Enfermedades isquémicas del corazón & 12,9 \\
\hline Enfermedades cerebrovasculares & 8,7 & Enfermedades cerebrovasculares & 8,7 \\
\hline Síntomas, signos y afecciones mal definidas & 5,2 & $\begin{array}{l}\text { Enfermedades crónicas de vías respirato- } \\
\text { rias inferiores }\end{array}$ & 5,1 \\
\hline $\begin{array}{l}\text { Agresiones (homicidios), inclusive se- } \\
\text { cuelas }\end{array}$ & 4,5 & Síntomas, signos y afecciones mal definidas & 4,5 \\
\hline $\begin{array}{l}\text { Enfermedades crónicas de vías respirato- } \\
\text { rias inferiores }\end{array}$ & 4,5 & Infecciones respiratorias agudas & 3,5 \\
\hline Infecciones respiratorias agudas & 4,0 & Diabetes mellitus & 3,5 \\
\hline Diabetes mellitus & 3,7 & Enfermedades del sistema urinario & 3,4 \\
\hline Enfermedades hipertensivas & 3,6 & Enfermedades hipertensivas & 3,4 \\
\hline Residuo & 3,6 & Otras enfermedades del sistema digestivo & 3,2 \\
\hline Enfermedades del sistema urinario & 3,6 & $\begin{array}{l}\text { Accidentes de transporte terrestre, inclu- } \\
\text { sive secuelas }\end{array}$ & 3,2 \\
\hline Otra & 43,6 & Otra & 48,5 \\
\hline \multicolumn{2}{|l|}{ Bogotá D. C. } & \multicolumn{2}{|l|}{ Leticia } \\
\hline Enfermedades isquémicas del corazón & 14,8 & Infecciones respiratorias agudas & 10,5 \\
\hline Enfermedades cerebrovasculares & 7,2 & Enfermedades isquémicas del corazón & 8,8 \\
\hline $\begin{array}{l}\text { Enfermedades crónicas de vías respirato- } \\
\text { rias inferiores }\end{array}$ & 6,8 & Enfermedades cerebrovasculares & 6,1 \\
\hline $\begin{array}{l}\text { Agresiones (homicidios), inclusive se- } \\
\text { cuelas }\end{array}$ & 4,9 & $\begin{array}{l}\text { Lesiones autoinfligidas intencionales (sui- } \\
\text { cidios), incluso secuelas }\end{array}$ & 6,1 \\
\hline Otras enfermedades del sistema digestivo & 4,0 & Síntomas, signos y afecciones mal definidas & 5,3 \\
\hline Enfermedades hipertensivas & 3,6 & Enfermedad por el vIH/SIDA & 4,4 \\
\hline Diabetes mellitus & 3,4 & Diabetes mellitus & 4,4 \\
\hline Residuo de tumores malignos & 3,4 & Tumor maligno del estómago & 3,5 \\
\hline $\begin{array}{l}\text { Enfermedad cardiopulmonar, de la cir- } \\
\text { culación pulmonar y otras enfermedades } \\
\text { del corazón }\end{array}$ & 3,2 & Tumor maligno hígado y vías biliares & 3,5 \\
\hline
\end{tabular}




\begin{tabular}{|c|c|c|c|}
\hline Causa & $\%$ & Causa & $\%$ \\
\hline Síntomas, signos y afecciones mal definidas & 3,0 & Tumor maligno del útero & 3,5 \\
\hline Otra & 45,7 & Otra & 43,9 \\
\hline \multicolumn{2}{|l|}{ Medellín } & \multicolumn{2}{|l|}{ Pasto } \\
\hline Enfermedades isquémicas del corazón & 14,3 & Enfermedades isquémicas del corazón & 12,5 \\
\hline $\begin{array}{l}\text { Agresiones (homicidios), inclusive se- } \\
\text { cuelas }\end{array}$ & 11,7 & Enfermedades cerebrovasculares & 8,7 \\
\hline $\begin{array}{l}\text { Enfermedades crónicas de vías respirato- } \\
\text { rias inferiores }\end{array}$ & 7,5 & $\begin{array}{l}\text { Enfermedades crónicas de vías respirato- } \\
\text { rias inferiores }\end{array}$ & 6,9 \\
\hline Enfermedades cerebrovasculares & 6,5 & Agresiones (homicidios), inclusive secuelas & 6,8 \\
\hline Infecciones respiratorias agudas & 4,1 & Otras enfermedades del sistema digestivo & 4,7 \\
\hline $\begin{array}{l}\text { Tumor maligno de tráquea, bronquios y } \\
\text { pulmón }\end{array}$ & 3,8 & Enfermedades hipertensivas & 3,8 \\
\hline Enfermedades sistema urinario & 3,5 & Diabetes mellitus & 3,7 \\
\hline Otras enfermedades del sistema digestivo & 3,1 & Infecciones respiratorias agudas & 3,6 \\
\hline Residuo de tumores malignos & 3,0 & Tumor maligno del estómago & 3,3 \\
\hline $\begin{array}{l}\text { Accidente de transporte terrestre, inclu- } \\
\text { sive secuelas }\end{array}$ & 3,0 & Residuo & 3,0 \\
\hline Otras & 39,5 & Otras & 43,0 \\
\hline
\end{tabular}

Fuente: DANE, 2011

TABLA A5. Principales indicadores del perfil epidemiológico de Barranquilla, Bogotá, Bucaramanga, Leticia, Medellín y Pasto, 2010

\begin{tabular}{|l|l|l|l|l|l|l|}
\hline Indicador & $\begin{array}{l}\text { Barran- } \\
\text { quilla }\end{array}$ & Bogotá & $\begin{array}{l}\text { Bucara- } \\
\text { manga }\end{array}$ & Leticia & $\begin{array}{l}\text { Mede- } \\
\text { llín }\end{array}$ & Pasto \\
\hline $\begin{array}{l}\text { Tasa de mortalidad infantil } \\
\text { X 1000 nacidos vivos }\end{array}$ & 14,72 & 11,7 & 10,97 & 42,72 & 13,7 & 14,42 \\
\hline $\begin{array}{l}\text { Razón de mortalidad mater- } \\
\text { na x 100000 nacidos vivos }\end{array}$ & 47 & 39,1 & 0,0 & $\begin{array}{l}18,9(2009) \\
(2)\end{array}$ & 17,5 & $0,0(3)$ \\
\hline Cobertura vacunación (\%) & \multicolumn{7}{|l|}{} \\
\hline DPT & 99 & 94,2 & 120 & 98,3 & $93,7(6)$ & $85,7(3)$ \\
\hline BCG & 116 & 101,1 & 100 & 109.5 & 108 & $82,2(3)$ \\
\hline Polio & 98 & 94,2 & ND & 98.3 & 93,5 & 80,5 \\
\hline HB & 99 & 93,8 & ND & 98.3 & 93,6 & $85,6(3)$ \\
\hline $\begin{array}{l}\text { Porcentaje de embarazo en } \\
\text { adolescente }\end{array}$ & 17,4 & 17,5 & $\begin{array}{l}23(2009) \\
(5)\end{array}$ & 24,4 & $15,5(7)$ & $9,9(2011)$ \\
\hline Porcentaje de desnutrición & \multicolumn{7}{|l|l|l|l|l|l|}{} \\
\hline Aguda & 1,3 & ND & $2,8(5)$ & $4.1(2007)$ & ND & $3.64(2011)$ \\
\hline Crónica & 19,9 & 11,0 & $3,6(5)$ & $30(2007)$ & $8,5(4)$ & $0.88(2011)$ \\
\hline Global & 3,6 & 8,4 & $3,5(5)$ & $14,7(2007)$ & $1,7(4)$ & $2,75(2011)(3)$ \\
\hline
\end{tabular}

* ND: no hay datos disponibles

Fuentes: 1) Oquendo, Gómezy Molina, 2014;2) Gobernación de Amazonas, 2011;3) Alcaldía de Pasto, Secretaría de Salud, 2012; 4) Alcaldía de Medellín, Secretaría de Bienestar Social, 2012; 5) Programa de Naciones Unidas para el Desarrollo y Alcaldía de Bucaramanga, 2012; 6) Medellín Cómo Vamos, 2011; 7) Ministerio de Salud y Protección Social, 2013 